\title{
sciendo
}

\section{A Dilemma for Saulish Skepticism: Either Self-Defeating or Not Even Skepticism}

\author{
Samuel Director \\ University of Colorado, Boulder \\ DOI: $10.2478 /$ disp-2018-0001 \\ BIBLID [0873-626X (2018) 48; pp.43-55]
}

\begin{abstract}
Jennifer Saul argues that the evidence from the literature on implicit biases entails a form of skepticism. In this paper, I argue that Saul faces a dilemma: her argument is either self-defeating, or it does not yield a skeptical conclusion. For Saul, both results are unacceptable; thus, her argument fails.
\end{abstract}

\section{Keywords}

Saul, skepticism, implicit-bias, self-defeat, rationality.

Jennifer Saul argues that the evidence from the literature on implicit biases entails a form of skepticism. In this paper, I argue that Saul faces a dilemma: her argument is either self-defeating, or it does not yield a skeptical conclusion. For Saul, both results are unacceptable; thus, her argument fails.

In section I, I explain Saul's argument from implicit bias to skepticism. In section II, I advance the above-mentioned dilemma.

\section{Saul's argument from implicit bias to skepticism}

For clarity, I have reconstructed Saul's argument in premise-conclusion form. It runs as follows:

(1) human rational faculties are heavily affected by implicit biases.

(2) if human rational faculties are heavily affected by implicit biases, then we should be skeptical about the reliability of our rational faculties. 
(3) thus, we should be skeptical about the reliability of our rational faculties $(2,1)$.

With the argument outlined, I explain Saul's defense of each premise. ${ }^{1}$

(1) human rational faculties are heavily affected by implicit biases.

As Saul defines them, implicit biases "are largely unconscious... [and] automatic tendencies to associate certain traits with members of particular social groups" (Saul 2012: 244). Specifically, these biases tend to make us "judge members of stigmatized groups more negatively" (Saul 2012: 244). As Saul (2012: 244-5) argues, the psychological literature on this topic shows that our faculties are heavily influenced by implicit biases. She points to several key areas in which research has shown our faculties are infected with bias. Studies have shown that the perceived racial identities of names on otherwise equal CVs cause us to judge them differently, that the prestige of a scholar's institution heavily influences the probability of favorable responses from journals, and that our perceptions of identical situations are likely to be altered by the racial identity of the people in them. This list is not exhaustive of the ways in which our faculties are influenced by implicit biases; rather, Saul intends this list to be a small sample of a broader phenomenon. Given all of this, Saul claims that our faculties are pervasively affected by the influence of implicit biases.

(2) if human rational faculties are heavily affected by implicit biases, then we should be skeptical about the reliability of our rational faculties.

Saul gives a two-step argument in defense of premise (2); first, she argues that the evidence about implicit biases should make us skeptical about our beliefs that come from individuals within marginalized groups; second, she argues that this skepticism about beliefs that come from individuals from marginalized groups entails a broader skepticism about the reliability of our rational faculties.

First, Saul holds that evidence about implicit biases should make

\footnotetext{
${ }^{1}$ The reader should know in advance that I will be extensively quoting from the text; as I will show later in this paper, Saul's argument, at several points, is ambiguous; by using her exact words whenever possible, I will reduce the chance of misconstruing her argument.
} 
us skeptical about our beliefs that come from marginalized individuals. As she argues, there is evidence that, when we think that the person giving an argument or testimony is from a marginalized group, our biases make us more likely to negatively appraise this individual's statements. From this, Saul infers that we should be skeptical about our beliefs that come from marginalized individuals. As she says:

We have very good reason to suppose that we are systematically making errors caused by our unconscious biases related to social categories (Saul 2012: 250, emphasis added).

My claim is that we're likely to be making errors... It's not that we're likely to get some really difficult technical bits wrong, or that we're likely to get things wrong if we're really exhausted...we're likely to let the social identity of the person making an argument affect our evaluation of that argument (Saul 2012: 249, emphasis added).

In these passages, Saul states that the influence of implicit bias shows that we are likely making errors whenever we evaluate a statement from a person in a marginalized group. To make an error in assessing these statements does not mean that we are slightly off the mark; rather, to be in error means that our beliefs (in this domain) are likely unjustified. As Louise Antony says, according to Saul, "the data about implicit bias tell us that, at least in certain domains, it is likely that we are not warranted in believing what we believe" (Antony 2016: 258). From all of this, Saul concludes that we should be skeptical about our beliefs that come from marginalized individuals.

Saul then claims that this local form of skepticism has global implications. As she argues, the fact that we are biased toward people from marginalized groups entails that we should endorse a more global skepticism.

Before continuing, it is important to make an exegetical point. Saul's argument is ambiguous; at points, it appears to be an argument for a more global skepticism, and at points it appears to be an argument for a more local skepticism. For example, at one point she claims that her argument does not entail that "we might be mistaken about everything, or even everything in the external world...but it does mean that we have good reason to believe that we are mistaken about a great deal" (Saul 2012: 243). This passage suggests that she does not intend to endorse a global form of skepticism. However, I argue that, 
overall, the textual evidence points in favor of reading Saul as endorsing the more global option. ${ }^{2}$ And, I am not alone in this interpretation. Michael Brownstein clearly shares my interpretation; as he says:

Some have suggested that the facts about implicit bias warrant a 'global' skepticism toward our capacities as epistemic agents (Saul 2012). (Brownstein 2017). ${ }^{3}$

Additionally, my interpretation is echoed by Duncan Pritchard and A. John Carter:

Saul's route from observations about implicit bias to a form of scepticism about knowledge proceeds by first noting that facts about implicit biases show that 'we have very good reason to suppose that we are systematically making errors caused by our unconscious biases related to social categories' (Saul 2013a, 250). If such judgements related to social categories were rare, then this would motivate only a very localized form of scepticism about knowledge. According to Saul, however, such judgements are widespread... one pervasive such arena is that of testimony... what goes for our assessments of testimony applies mutatis mutandis to other social-epistemic activities, such as considering questions, judging arguments, listening to contributions, and so on. It thus follows that Saul has potentially identified an empirical basis for scepticism about a reasonably wide class of knowledge (Pritchard and Carter 2016).

And, Saul herself strongly indicates that she endorses a more global form of skepticism. As she argues, this bias-induced skepticism entails that we cannot trust our faculties:

What we know about implicit biases shows us that we have very good reason to believe that we cannot properly trust our knowledge-seeking faculties ( Saul 2012: 243).

We are making errors in perception due to implicit bias. The very data

${ }^{2}$ One might object that, for Saul, the skepticism ends here and does not generalize to other domains. In other words, one might argue that Saul's skepticism is only intended to be about beliefs formed in certain social domains (i.e. in reference to marginalized individuals) and that this skepticism does not generalize to our cognitive faculties in general. Based on the evidence from the text that I cite in the coming pages, I argue that Saul does view her skepticism as generalizing from the social domain to all other domains.

${ }^{3}$ Brownstein 2017. 
from which we begin in thinking about the world-our perceptionscannot be relied upon to be free of bias (Saul 2012: 249).

Additionally, Saul's skepticism entails that we should be skeptical about our abilities as seekers of truth:

The literature on implicit bias shows us...that we really should not trust ourselves as inquirers (Saul 2012: 253).

The literature on implicit bias shows us not just that our habits can't be relied on to lead us to truth, but also that...they are likely to be based in values that we...find repugnant. It is difficult to see how we could ever properly trust these [our cognitive habits] again once we have reflected on implicit bias (Saul 2012: 254).

Simply put, Saul's skepticism about beliefs from marginalized individuals entails a much more global skepticism about both our faculties and our rational abilities. If this is not evidence enough, Saul's claims about the implications of her view clearly indicate that she endorses a more global skepticism:

Much of our knowledge comes from testimony, or from arguments or evidence that we are presented with. Those testifying, or presenting are generally (though not always) perceived by us as members of social groups. Moreover, much of the knowledge we already have has come to us in this way. Our acceptance or rejection of testimony, arguments, evidence and the like has shaped the worldviews we have now. And this acceptance or rejection was, we can be fairly certain, distorted by the perceived social groups of those presenting the testimony, arguments or evidence (Saul 2012: 251).

It [the doubt from bias] is broad in its scope. It arises with regard to any beliefs that might have been unconsciously shaped by our implicit attitudes about members of social categories, and these are an enormous number of our beliefs. Moreover, we don't in general even know which beliefs these are. This gives it the kind of breadth that leads to a much greater worry than the very containable concerns about probabilistic reasoning (Saul 2012: 252-3).

Many of our philosophical beliefs-those beliefs we take to have been arrived at through the most careful exercise of reason-are likely to be wrong (Saul 2012: 247). 
We have very good reason to suppose that we are systematically making errors caused by our unconscious biases related to social categories (Saul 2012: 250).

Given all of this, it is clear that Saul does, in fact, endorse a more global skepticism. ${ }^{4}$ And, with that, her argument for premise (2) is complete. And, the conclusion follows:

(3) thus, we should be skeptical about the reliability of our rational faculties $(2,1)$.

One might ask if this skeptical problem could be avoided by bias reduction techniques. If that were true, then the skeptical conclusion of (3) could be avoided. On Saul's view, this is not a promising route of objection. Saul does discuss how we can work to make ourselves less biased. But, there are two important things to notice about the bias reduction methods that Saul mentions: (1) they are only forward

${ }^{4}$ One might wonder, precisely, how global Saul's skepticism is. For example, she says the following in reference to her argument: "this does not mean that we might be mistaken about everything, or even everything in the external world... but it does mean that we have good reason to believe that we are mistaken about a great deal" (Saul 2012: 243). As I have stated previously, this passage suggests that there is some ambiguity in what Saul's position is; she may be claiming (1) that we should be skeptical about all of our beliefs or that (2) we should be skeptical about most, but not all, of our beliefs. The passage just quoted seems to suggest that we should interpret Saul along the lines of (2). If this is true, then Saul does not endorse a fully global skepticism. I have several responses to this line of reasoning. First, the majority of the textual evidence (cited previously) suggests that Saul endorses (1). Second, as a helpful referee comment made clear to me, Saul's view not only calls into question many of our beliefs, but it also holds that we cannot know which of our beliefs have been called into question, as any individual belief could have been influenced by bias. As a result, Saul's view entails that we cannot know which of our beliefs are biased, which means that we ought to regard all of them as being biased. In other words, if I know that many of my beliefs are unjustified due to the influence of implicit biases, and if I do not know which beliefs those are, this gives me a reason to distrust all of my beliefs (2012: 252-3). In that manner, Saul is committed to (1). Third, even if Saul is endorsing (2) rather than (1) my argument would still succeed. Saul very clearly indicates that she thinks our faculties, our abilities as inquirers, and our intellectual habits are unreliable. So long as she claims this, my argument still succeeds, because these are the very belief forming mechanisms that she must use in order to develop her argument, which renders her position vulnerable to the self-defeat objection. So, even if some of our beliefs are not defeated by our biases, this would not affect my argument. 
looking, and (2) they have only a minimal chance of success. First, Saul acknowledges that the bias reduction methods referenced in her paper can only help us to become less biased in the future; these methods cannot tell us if our currently held beliefs are influenced by bias. As she asks, "so is there anything that one can do?," to which she answers, "not for past cases like these. However, I can act so as to reduce the likelihood of this happening in future instances" (Saul 2012: 257). Second, as Saul explains them, these bias reduction techniques will only be successful if society changes in highly unlikely ways. As she says, "the only way to be fully freed from the grip of bias-related doubt is to create a social world where the stereotypes that now warp our judgments no longer hold sway over us" (Saul 2012: 260-1). As this is not likely to happen soon, Saul's skepticism is likely to persist.

\section{A dilemma for Saul}

I argue that Saul's view faces a dilemma: (1) if Saul's argument is strong enough to generate skepticism, then it is self-defeating, or (2) if her argument is weak enough to not entail self-defeat, then it does not get her to a skeptical conclusion. Thus, Saul is either committed to a self-defeating position, or she is no longer arguing for a form of skepticism; either way, her skeptical conclusion fails.

\subsection{Horn 1 of the dilemma}

If Saul's argument is strong enough to generate skepticism, then it is self-defeating. ${ }^{5}$ Saul's argument arrives at a skeptical conclusion by calling into question the reliability of our rational faculties and abilities as inquirers (henceforth 'faculties'). If her argument succeeds, then it shows us that our faculties are generally unreliable. However, the very same rational faculties that Saul's argument calls into question are necessary in order for her to formulate her argument. In other words, to argue for skepticism about our rational faculties, Saul inevitably must use the very faculties that her argument is meant to

\footnotetext{
${ }^{5}$ I am aware that self-defeat objections are often advanced against skepticism. However, what is new about my argument is that it shows that an old objection is still successful against a new form of skepticism.
} 
impugn. After all, to acquire the empirical evidence about implicit biases that she uses in her argument, Saul must have used her perceptual faculties to read psychology articles, she must have accepted the testimony of psychologists, and she must have trusted her abilities as a seeker of truth. Thus, to have learned the empirical information used in her argument, Saul used her perception, relied on testimony, and trusted her rational abilities, all of which are called into question by her argument. By her own reasoning, she should doubt the evidence used in her argument, because it was acquired using faculties and abilities that she believes to be unreliable. Furthermore, the psychologists that Saul cites must have, in the process of conducting their research, relied on the testimony of participants in their studies, must have used their perceptual faculties to make observations, etc. Essentially, for Saul to have acquired the empirical information used in her argument, and in order for the researchers Saul cites to have acquired their data, testimony, perception, and other faculties must have been relied on. In short, both Saul and the researchers that she cites must have relied on their faculties in order to formulate their arguments and conduct their research. Yet, Saul's argument is meant to generate a skeptical conclusion about the reliability of these very faculties. Again, she argues that "what we know about implicit biases shows us that we have very good reason to believe that we cannot properly trust our knowledge-seeking faculties" (Saul 2012: 243). This leads to a clear self-defeat problem: if we agree with Saul's conclusion (that we cannot trust our faculties and should be skeptical about the beliefs that they generate), then we must doubt her conclusion, because it relies on those very faculties. In so far as self-defeating arguments impugn themselves and are incoherent, we should not be troubled by them. Thus, if Saul's argument entails skepticism, then it fails.

One might object to this line of reasoning in several ways. For the rest of this section, I consider several objections to my self-defeat argument.

Objection 1:

First, the objector might argue that there is something sophistical and, so to speak, suspicious, about this argument; it seems to use a trick in reasoning in order to conclude that we should not worry at all about the influence of implicit biases on our faculties. And, as 
the objector holds, this seems too easy, and it discards the very real influence of implicit biases on our beliefs.

In response, I argue that this objection rests on a misunderstanding of my argument. The objector is correct that this self-defeat problem is not sufficient grounds to ignore our biases altogether; but, that is not my claim. Rather, my claim is simply that, if Saul's argument generates a genuine form of skepticism, then it is self-defeating. As will be seen in the next section, Saul can reformulate her argument to avoid this self-defeat objection while still taking very seriously the epistemic threat posed to our beliefs by implicit biases. Essentially, accepting my self-defeat objection does not license one to simply discard the evidence from the implicit bias literature; my argument is only meant to show that this evidence cannot generate skepticism without entailing self-defeat.

Objection 2:

Second, one might object that Saul can avoid this self-defeat problem if she were to use the aforementioned bias-reduction techniques on herself. In short, if Saul could use these methods to reduce her own biases, then she could advance her argument without defeating herself, as her own faculties would not be unreliable. ${ }^{6}$

I have several responses to this objection. First, Saul herself expresses strong doubts about the efficacy of these bias reduction techniques. As I stated earlier, Saul argues that these strategies are only forward looking, meaning that they cannot help us to remove the influence of bias from beliefs we have formed in the past (2012: 257). And, she also argues that these strategies have a minimal chance of success (2012: 260-1). Given this, it seems that bias reduction techniques do not help Saul to escape the self-defeat objection, as she herself does not put much trust in these techniques.

Second, even if Saul could successfully implement these bias reduction strategies on herself, this would still not allow her to escape the self-defeat objection. The psychologists who Saul cites in defense of her argument, like all humans, are biased. So, unless Saul has evidence that the majority of the psychologists she cites have

${ }^{6}$ I am thankful to an anonymous referee for raising this objection, as well as objection 3 . 
conducted extensive bias reduction routines on themselves, the data that she uses to form her argument would still be biased. Thus, even if Saul could reduce her own biases when conducting research, the very evidence that she draws from is likely to be infected by biases. This means that she still faces the self-defeat objection, because the empirical evidence that she uses to justify her skepticism about the reliability of our faculties would, itself, be generated by the faculties of individuals who are biased. So, even if Saul is unbiased, she still argues that we should not trust our faculties based on evidence that comes from the same faculties that she has called into question, namely the faculties of people in general.

\section{Objection 3:}

Third, one might object with a dilemma; either one of the following is true: (1) if Saul was biased when she conducted her research and formed her argument, then her conclusion is correct, namely that our faculties are biased and cannot be trusted, or (2) if Saul was not biased when she conducted her research, then she has correctly inferred her conclusion from the evidence. Either way, argues the objector, Saul's conclusion (that our faculties are biased and thus unreliable) follows without self-defeat.

If (2) is correct, then Saul could justifiably infer that our faculties are biased. After all, she would be using empirical evidence to justify her belief, and she would have no reason to distrust this evidence. However, as I have argued, option (2) is, in fact, not the case. Saul's argument calls into question the very faculties that she used to form this argument; in that manner, her argument and her research are affected by bias-related skepticism. This leaves option (1). However, this option does not justify Saul's conclusion. It may turn out to be the case that we are all heavily affected by implicit biases, but if our only evidence in support of this claim is defeated, then we cannot justifiably believe that we are biased. For example, it may very well be the case that anti-realism about the external world is true. However, if it turns out that anti-realism about the external world is selfdefeating, we would lack justification for believing in this view, even if it is true. Saul's view is analogous to this. Under option (1), it may be true that we are all heavily biased, but Saul would have no justification for holding this belief. Thus, I conclude that the objector's 
dilemma fails, because option (2) is not the case, and because option (1) does not yield Saul's desired conclusion.

\subsection{Horn 2 of the dilemma}

If Saul wants to avoid this self-defeat objection, then she can modify her argument so that it entails a significant, but non-skeptical, credence reduction in the reliability of our faculties. After all, if her argument claimed that we should significantly reduce our credences in many of our beliefs without reaching a skeptical $(0.5)$ credence in these beliefs, then the self-defeat objection would not apply. ${ }^{7}$ The self-defeat objection only applies to her argument if she claims that we cannot trust our faculties; if she instead claims that we should significantly decrease our confidence (without being skeptical) about these faculties, then her argument is not self-defeating. She can, without defeating herself, use her faculties in order to conclude that that we should lower our confidence in these very faculties. This position, as I see it, avoids self-defeat. For example, suppose that I have a 0.8 credence in P ('my faculties are reliable'); if Saul's argument concludes that I should reduce my credence in $\mathrm{P}$ by 0.2 (a non-trivial amount), then I would arrive at a 0.6 credence in P. This is a less confident attitude toward $\mathrm{P}$, but it is not a skeptical position. This line of reasoning is not self-defeating. Thus, if Saul revised her argument in this way, she could avoid the self-defeat objection.

However, if Saul modifies her argument in this manner, then she faces the second horn of the dilemma: if her argument is weak enough to not entail self-defeat, then it does not entail skepticism. Thus, if Saul modifies her position in this way, then she can no longer argue for a form of skepticism.

Saul's revised argument would run as follows (with the changes from the original premises italicized). Premise (1) would remain the same:

(1) human rational faculties are heavily affected by implicit biases.

${ }^{7}$ There is disagreement about, precisely, what credence constitutes skepticism or suspension of belief. For the sake of clarity, I will stipulate that a credence of 0.5 or below in $\mathrm{P}$ is skepticism about $\mathrm{P}$ and that anything above 0.5 in $\mathrm{P}$ constitutes belief, however weak, in P. 
Premise (2), however, would have to be the following:

$\left(2^{*}\right)$ if human rational faculties are heavily affected by implicit biases, then we should significantly reduce our confidence in the reliability of our rational faculties (without becoming skeptical about our faculties).

It is important to note that claim (3) of Saul's original argument does not follow from (2*) and (1). Saul's original (3) concludes that we should be skeptical about the reliability of our rational faculties. Simply put, from the claim that we should be less confident in our faculties, it does not follow that we should be skeptical about our faculties. Rather, $\left(3^{*}\right)$ follows from (1) and $\left(2^{*}\right)$ :

$\left(3^{*}\right)$ thus, we should significantly reduce our confidence in the reliability of our rational faculties (without becoming skeptical about our faculties) $\left(2^{*}, 1\right)$.

To review, if Saul alters her position and claims that the influence of implicit biases entails a non-skeptical credence reduction in the reliability of our faculties, then she must endorse (2*) rather than (2). From (1) and $\left(2^{*}\right),\left(3^{*}\right)$ (not Saul's original claim (3)) follows. Clearly, this revised argument does not reach a skeptical conclusion. At best, this revised argument mandates that we should reduce our credences in many of our beliefs, but it does not require us to be skeptical about our beliefs.

\section{Conclusion}

In total, Saul's argument is either strong enough to entail skepticism, in which case it is self-defeating, or her argument is weak enough to avoid self-defeat, in which case it no longer entails skepticism. Thus, Saul's argument cannot generate a skeptical conclusion. From this, I conclude that Saulish skepticism fails to be a plausible form of skepticism. Ultimately, this may be good news for Saul. If I am correct, then her argument cannot entail skepticism, but it can still entail a significant amount of confidence reduction in many of our beliefs. In that manner, my argument shows that Saul's position is much stronger if she endorses a less radical conclusion. ${ }^{8}$

${ }^{8}$ I would like to thank Bob Pasnau, Mike Huemer, and Chris Heathwood for 
Samuel Director

University of Colorado, Boulder

Philosophy Department

Boulder, CO 80309

Samuel.Director@colorado.edu

\section{References}

Antony, Louise M. 2016. Bias: friend or foe? In Implicit Bias and Philosophy, Volume 1: Metaphysics and Epistemology, ed. by Michael Brownstein and Jennifer Saul. Oxford: Oxford University Press.

Brownstein, Michael. 2017. Implicit bias. The Stanford Encyclopedia of Philosophy. https://plato.stanford.edu/entries/implicit-bias/\#Epi.

Carter, J. Adam; and Duncan Pritchard. 2016. Cognitive bias, scepticism and understanding. In Explaining Understanding: New Perspectives from Epistemology and Philosophy of Science, ed. by Stephen R. Grimm, Christopher Baumberger and Sabine Ammon. New York: Routledge.

Saul, Jennifer. 2012. Skepticism and implicit bias. Disputatio 37: 243-63.

their helpful comments during various stages of this paper. I would also like to thank two anonymous reviewers at Disputatio for their helpful comments. Finally, thanks are due to Emily Erickson for all of her help. 